\title{
Patients with obesity use of activity monitors when attending a weight-loss programme-a qualitative study
}

Ingrid Sørdal Følling ( $\square$ ingfoll@gmail.com )

Norwegian University of Science and Technology (NTNU) https://orcid.org/0000-0002-7745-9480 Line Oldervoll

Norges Teknisk-Naturvitenskapelige Universitet Fakultet for Medisin og Helsevitenskap

Christina Hilmarsen

Norges Teknisk-Naturvitenskapelige Universitet Fakultet for Medisin og Helsevitenskap

Ellen M I Ersfjord

St. Olavs Hospital

Research article

Keywords: Obesity, Activity monitors, Weight-loss programme, Health habits, Qualitative research

Posted Date: June 17th, 2020

DOI: https://doi.org/10.21203/rs.3.rs-33462/v1

License: (a) (i) This work is licensed under a Creative Commons Attribution 4.0 International License.

Read Full License 


\section{Abstract}

Background: Obesity is a major health concern in western countries. In Norway, patients with obesity can attend weight-loss programmes, which focus on changes in dietary and physical activity habits. Use of self-monitoring is advocated when changing dietary and physical activity habits for adults with obesity. This study aimed to explore the experiences of patients with obesity who used activity monitors while attending a weight-loss program.

Methods: Patients with body mass index $(\mathrm{BMI})>35 \mathrm{~kg} / \mathrm{m}^{2}$ with weight related comorbidities or a $\mathrm{BMI}>$ $40 \mathrm{~kg} / \mathrm{m}^{2}$ referred to an intermittent weight-loss programme were recruited into this study. They were introduced to one of three different activity monitors, Fitbit Zip ${ }^{T M}$, Mio Fuse $^{T M}$, or Mio Slice ${ }^{T M}$. Semistructured interviews were performed with patients six months into the weight-loss programme. Thematic analysis was applied when analysing the data.

Results: Of the 29 informants (aged 21 to 66 years) interviewed, 59\% were female. Their experience with activity monitors was related to their adherence to the weight-loss programme. Two main themes emerged from the informants stories: 1. "Activity monitors visualize proof of effort or failure to change health habits". 2. "Activity monitors act as a positive or negative enforcer when incorporating change".

Conclusions: Using activity monitors either strengthens or undermines patients' attempts to change health habits when attending a weight-loss program. Our findings suggest a need for more individualized weight-loss programmes for patients with obesity.

Trial Registration: The study was registered in ClinicalTrials.gov on July 72016 , with the registration number NCT02826122 and URL: https://clinicaltrials.gov/ct2/show/NCT02826122? term $=$ NCT02826122\&draw $=2 \&$ rank $=1$.

\section{Background}

The prevalence of obesity is alarming and continues to rise in western countries [1]. To reduce obesity, weight-loss programmes promote changes in diet and physical activity [2]. Weight-loss programmes for adults with obesity can lead to clinically important weight loss (5\% of baseline weight) [3]. Thus, achieving weight loss is challenging and weight maintenance is hard $[2,4]$. To help modify changes in diet and physical activity for adults with obesity, the use of activity monitors as a means of selfmonitoring is advocated by the World Health Organization and in international policy [5].

There has been scepticism regarding the use of self-monitoring technologies to support individuals' behavioural change [6]. Recording and measuring behaviours or bodily functions can be reductionist, disempowering and act disciplining rather than motivational [7]. Nevertheless, the purpose of selfmonitoring is to increase awareness of the body and one's health behaviour [8]. Studies on individuals who used activity monitors have found that it may improve health management [9-10] and that it strengthens reflections regarding improvement of the self [11]. It was also found that adding activity 
monitors to interventions for adults with overweight or obesity may increase physical activity [12]. A recently published systematic review and meta-analysis of randomized controlled trials (RCT) found that wearable physical activity monitors had a moderate and significant effect on body weight and waist circumference and a large and significant effect on body mass index (BMI) [13]. However, participants in such studies have been recruited from the general population and may, to a high degree, have been early adopters of technology or already highly motivated to make changes in their diet or increase physical activity level [14]. Qualitative studies on how individuals with overweight or obesity experience selfmonitoring have often used subsamples from RCTs [15], which means that these informants are more engaged in self-monitoring than if they had been recruited in another way (i.e., a random sample of patients in a weight-loss programme). To the best of our knowledge, there is no study on how a sample of patients with obesity recruited to an intermittent weight-loss programme experience the use of activity monitors. Thus, the aim of the present study was to explore how patients with obesity experience using activity monitors while attending an intermittent weight loss program.

\section{Methods}

\section{Design}

This study employed a qualitative design with semi-structured in-depth interviews to explore how patients with obesity experience activity monitors while attending an intermittent weight loss program.

\section{Setting}

\section{The weight-loss programme}

Patients with body mass index $(\mathrm{BMI})>40 \mathrm{~kg} / \mathrm{m}^{2}$ (or a $\mathrm{BMI}>35 \mathrm{~kg} / \mathrm{m}^{2}$ with weight related comorbidities) were referred by the Obesity Clinic at St. Olavs Hospital, Trondheim, Norway, to an intermittent weight-loss programme at LHL-klinikkene Røros (LHL-R).

The weight-loss programme took place over a period of two years (October 2016-October 2018) and patients had four intermittent stays (approximately every 5-6 month) at LHL-R, with each stay lasting three weeks. A multidisciplinary team consisting of a physician, dietician, physiotherapist, occupational therapist, nurse and psychiatric nurse trained in behavioural cognitive therapy (BCT) were responsible for the programme. The programme was based on current guidelines for the management of overweight and obesity in adults [16].

The weight-loss programme included physical activity, dietary sessions and BCT, from Monday to Friday every week during each stay. The physical activity part included two hours of theory in plenary and 31 hours of practical sessions. The physical activity programme offered various activities, focusing on being physically active through endurance and strength exercise. Dietary advice was offered in a one-hour lecture and four hours of group work, focusing on calories and nutrition, two hours of examining the ingredients and nutrition of groceries, and four hours of cooking. Dietary sessions focused on planning 
and preparing meals, as well as awareness of, and ways to modify, eating behaviour. Personalized meal plans and dietary advice targeted a calorie reduction of approximately 600 Kilocalories a day. Individual calorie restricted diets were based on the given estimate for resting metabolic rate. BCT included three hours of plenary sessions, four hours group work, and individual sessions. BCT was aimed at goal setting and increased awareness of maladaptive cognitions that contribute to the maintenance of emotional distress and problematic eating behaviour [17]. Topics covered were expectations towards attending the weight-loss programme, motivation and conflicting interests, excuses, compensatory strategies and foundation for change.

In addition, each participant's body composition was assessed using a bioelectrical impedance scale. Cardiovascular and metabolic risks were assessed using blood chemistry analysis, and physiology assessed using cardiorespiratory fitness test and blood pressure measurement. The team discussed test results with each participant individually.

\section{The activity monitors}

Three different activity monitors were used in this study. The FitBit Zip ${ }^{\mathrm{TM}}$ is a clip-on step counter that records and displays distance and estimates total energy consumption. The Mio Fuse ${ }^{\mathrm{TM}}$ and the Mio Slice ${ }^{\mathrm{TM}}$ are wristbands with integrated optical heart rate sensors, recording and displaying heart rate, calorie consumption and sleep hours. The Mio devices held a population-based algorithm calculating heart rate variability into Personal Activity Intelligence points (PAI)[18].

All three activity monitors display "time to move" reminders. When reaching the recommended 10.000 daily steps or 100 weekly PAl, the activity monitors displayed smiley faces and apps changed colour.

Activity monitors and respective mobile software applications were set-up for all patients, device pairing completed, and troubleshooting handled with help from personnel. They were free to stop using the activity monitors whenever they wanted.

\section{Recruitment}

All 56 patients who entered their first stay at LHL-R were introduced to one of the three different activity monitors (Fitbit Zip ${ }^{T M}$, Mio Fuse ${ }^{T M}$, or Mio Slice ${ }^{T M}$ ). During the patients' second stay at LHL-R, a random sample was recruited for this study. The team at LHL-R helped with the recruitment process. They informed the patients that participation in the study would not affect their participation in the weight-loss programme. Recruitment continued until saturation was met. Of the 56 patients, 31 agreed to an interview, and two declined, resulting in 29 informants for this study.

\section{Interviews}

Interviews were conducted between February and July 2017 at patients' second stay at LHL-R. The third author $(\mathrm{CH})$ performed the interviews, which had a mean duration time of 45 minutes. An audio recorder was used and field notes were made during each interview. 
A semi-structured interview guide was employed, the main question being "What are your thoughts about how the activity monitor affects your weight-loss?" Follow-up questions and probes were used to clarify and explore what they considered to be important, such as: "How do you experience the activity monitor?" "What did you like or dislike about the activity monitor?"

\section{Ethics}

The study was approved by the Regional Committee for Medical and Health research in central Norway (REK 2016/833). All informants received oral and written information about the study. They signed an informed consent form prior to the interview.

\section{Data analysis}

All interviews were transcribed verbatim and analyzed together with the field notes. The data was analysed thematically in six steps [19]. In the first step of the analysis, transcripts and field notes were read to obtain an overall impression of the material. A summary of transcripts and a list of preliminary themes that occurred was written. Second, all meaning units were extracted and sorted into codes. In the search for themes were all codes relevant to the aim discussed by all authors in the third step. The coauthors read three interviews each and the summary prior to the discussion. In the fourth step, the themes were reviewed, checking that each theme worked in relation to the codes and related data. Some themes were discarded, and some codes were revised returning to steps two and three. In the fifth step, all authors defined and named the themes after exploring: "what did this theme tell us?" and "how did each story fit the overall story of the data?"Naming the themes finalized this step. In the sixth and final step the results were written, including quotes that highlight informants' stories. The authors met repeatedly between October 2017 and March 2018, discussing themes and possible underlying patterns in the data.

All quotes were translated from Norwegian into English.

\section{Results}

The 29 informants were all Caucasian, aged between 21 to 66 years, with 59\% being females (Table 1). Most informants continued to use activity monitors at six months; however, most had changed to a different activity monitor. Reasons for changing to a different monitor included size of wristband, being too small or tight, or being too complicated.

Two main themes emerged from the informants' stories. In general, descriptions of their experience with activity monitors were aligned with their adherence (or lack thereof) to the weight-loss programme.

\section{Activity monitors visualize proof of effort or highlights failure to change health habits}

In about two thirds of the informants' stories, the activity monitors acted as proof of effort in the weightloss programme. The other third of the informants described activity monitors as highlighting their failure 
to change health habits. Quotes describing these two experiences with the activity monitor are presented in Table 2.

The informants who described activity monitors as evidence of effort emphasized how they themselves had asked professional help to change their health habits. They also said that they had recognized that their health habits needed adjustments both before entering the weight-loss programme and during their first stay at LHL-R. They described finding joy in experiencing new activities and pushing their own boundaries during the stays at LHL-R. Physical activity was mentioned as an investment in their bodies and health. For them, the activity monitor acted as evidence of their effort when displaying the regularity of the physical activity, as well as the distance covered and duration of the activity. Connecting the numbers with their own perceptions, they described how their bodies now responded differently compared to six months earlier when they started the weight-loss programme. When checking the activity monitors' physical activity log, they saw how they gradually were able to walk the same route in less time. They talked about how they had modified pre-set activity targets and adjusted their individual goals. The monitors' display motivated them to keep up with physical activity and diet. Both accumulated physical activity and calorie consumption on the monitor's display was used as guidance. The activity monitor was useful for monitoring progress in physical activity. Some told how they felt compelled to reach the recommended steps or activity points.

The informants who described activity monitors as highlighting their failure to change health habits said that their motivation for entering the weight-loss programme was primarily pleasing someone else, for example a next of kin or their general practitioner. These informants did not find the weight-loss programme helpful. They said they had never been physically active or enjoyed physical activity. Fear of pain and discomfort related to physical activity was frequently mentioned. They explained they did not manage to meet the goals they had set with the team initially in the weight-loss programme. In their stories, it was evident that they failed to follow diet and physical activity instructions, and they continued to make unhealthy choices. Low numbers on the activity monitors visualized their failure in following instructions. They talked about how the monitors made them aware of how little they walked compared to the recommendations, and they said they felt bad about this. It was their own responsibility and they were ashamed. They said they were to blame for not being able to change. In addition, they emphasized how every wrong decision, for example choosing a hot dog over fruit for a snack, or choosing the elevator over the stairs, made them feel bad about themselves. The activity monitor evidenced, and reinforced, their sense of failure.

\section{Activity monitors act as a positive or negative enforcer when incorporating change}

All informants said that daily obligations towards family, friends, work and leisure activities did not allow for several hours of physical activity every day when being home from the intermittent stays.

Thus, the informants who saw monitors as proof of their hard work described activity monitors as a source of support when incorporating change into everyday life. They exercised less than when at the intermittent stays, but regularly. By making small but feasible modifications they were able to incorporate 
recommendations from the weight loss program into everyday life. For them, every step and effort counted, and the activity monitors motivated them to continue to follow the instructions from the weightloss programme to the best of their ability. The monitor also helped in finding ways of becoming more active and planning for activity. One said:

"Activity monitors strengthen confidence in my ability to follow instructions. The constant surveillance of the body imposed by the monitor visualizes ability to change habits as proposed, and that is why it is a support for me in my work of changing health habits". Male 30-39 years

The informants who found that activity monitors highlighted their failure to change described how hard it was to live by the instructions from the weight-loss programme. They said that during their intermittent stays at LHL-R, reaching the activity targets was feasible, while at home it was impossible. They described how they struggled to incorporate changes from the weight-loss programme at home. They did not consider adjusting their activity targets to more realistic levels while at home. However, they were overwhelmed by feelings of defeat as they were unable to manage everything as they should. In addition, not reaching physical activity targets as programmed in their activity monitor amplified their description of "nothing I do makes a difference anyway".

"What I have really missed is the sensation that this change feels okay. It is just hard work. What the team at LHL-R told me to do when I was at the intermittent stay is not helping when I am home in my daily life. The activity monitor was interesting in the beginning, now it just feels like a burden, reminding me of what I should have done but did not do." Female 50-59 years

\section{Discussion}

The aim of this present study was to explore how patients with obesity experience activity monitors when being treated for overweight or obesity. In our results, after being introduced to activity monitors at their first stay in the weight-loss programme at LHL-R, most informants continued to use activity monitors after six months. However, the majority had replaced the monitor with a more suitable one. The informants' description of experiences with activity monitors was related to adherence (or lack of) to the weight-loss programme. Two main themes emerged from informants' stories: "Activity monitors visualize proof of effort or failure to change health habits" and "Activity monitors act as a positive or negative enforcer when incorporating change".

\section{Positive and negative experiences with activity monitors}

In our study, about two thirds of informants felt that the activity monitor acted as a proof of effort when attending the weight-loss program. These informants talked about the positive effects of being more physically active and enjoying the response of their bodies, and some continued to lose weight after starting at the weight-loss programme. The intention for weight-loss programmes for patients with obesity should always be to create healthier habits [19]. Previous quantitative studies have found that wearable technologies support physical activity interventions to reduce weight, waist circumference and 
BMI for individuals with overweight and obesity [20]. Some people with overweight and obesity manage to develop new habits, and goal setting and self-tracking can be effective techniques in doing so [5, 21]. The finding that informants in our study had positive experiences with the activity monitors contributes to other findings that activity monitors can help in the weight-loss process.

The informants with positive experience in our study were more likely to enter the weight-loss programme on their own initiative, whilst those with negative experience had external motivation for attending the weight-loss programme. This is in line with earlier findings that individuals motivated by own needs and desires find it easier to sustain new behaviour [22]. People who enter such programmes on their own initiative may be more ready for change [23]. They may be also more likely to acknowledge their weight and health problems. They could thereby be more prone to adhere to the activity monitor and develop new habits, both within physical activity and diet.

However, in our study, one third of the informants felt that the activity monitor evidenced their failure to change. These informants told they blamed themselves for being unable to change. Other studies have also found that patients may express self-blame for their failure to lose weight [24]. There may be negative psychological consequences of participating in weight-loss programmes, which could exacerbate continuing disparities in obesity, health and well-being [25]. These psychological consequences of participating in weight-loss programmes may include loss of self-efficacy and selfesteem [26], as well as increase in body dissatisfaction and social stigma [27]. Unfortunately, individuals who have successfully initiated a new habit will more often fail than succeed in maintaining the new habit over time [28]. Another qualitative study about changing health habits found that previous attempts to change was a barrier to new attempts to change [29]. As many previous studies have highlighted, weight maintenance is hard, and many people regain weight after participating in weight-loss programmes [2, 4]. In addition, for people struggling with overweight and obesity, the body metabolism reaction is to go back to the highest weight or more [30]. This again could enforce previous failures in weight-loss attempts and may result in more self-blame. In such cases, attending weight-loss programmes could be contraindicative if participation yields yet another failure. Based on our results, the use of activity monitors and the experience with it may indicate which patients will adhere to treatment and who will not. Our findings support the need for more individualized weight loss programmes for patients with obesity, especially for those who do not adhere to weight-loss programmes, focusing on finding strategies to help all patients with obesity.

\section{Strengths and limitations}

The interviews in this study took place at patients' second stay at LHL-R, six months after introducing activity monitors, and there is no data on the participants' experiences with the monitors during the total period of two years. Other studies has shown that initial interest in activity monitors is rapidly lost, whereas over a third of individuals purchasing commercially available activity monitors abandon the use within six months [6]. However, in our sample, only a few had abandoned the use within six months, with most having changed to a different monitor. 
Regarding the qualitative design of this study, we cannot generalize our findings to all patients with obesity using activity monitor. Even so, we believe our sample to be potentially more representative to adults with obesity than studies with open recruitment on participants with overweight and obesity [15]. Thus, our study adds new knowledge on the use of activity monitors for patients with obesity who attend weight-loss programs.

\section{Conclusion}

The results of this study suggest that using an activity monitor either strengthens or undermines patients' with obesity attempts to change health habits. The use of activity monitors should be recommended for only a selection of patients. Patients who entered the weight-loss programme on their own initiative responded more positively to the activity monitors than those who did not. Our findings highlight the need to focus on selection of patients with obesity that could benefit from attending weight-loss programmes. Further research should investigate the use of activity monitor in patients with obesity over longer time (<6 months).

\section{Declarations}

Ethics approval and consent to participate

All participants received oral and written information to enable them to make an informed choice about participating in the present study, and all participants signed an informed consent form. The study was approved by the Regional Committee for Medical and Health research in central Norway (REK 2016/833).

Consent for publication

Not applicable.

\section{Availability of data and materials}

The raw data supporting the findings in this article can be found at the Centre for Obesity Research (ObeCe), St. Olavs Hospital, Trondheim, Norway. Due to the Regional Committee for Medical and Health Research Ethics in Central Norway regulations, we have to secure the anonymity of the participants. In the raw data it is possible to identify the participants, and restrictions therefore apply to the availability of these data.

\section{Competing interests}

The authors declare no competing interests.

\section{Funding}

This research was funded by EXtraStiftelsen and Samarbeidsorganet, Helse Midt-Norge RHF. 
$\mathrm{CH}$ designed the study with guidance from LO. CH performed the data collection and was responsible for the analysis. EE, LO and ISF analysed parts of the data with $\mathrm{CH}$ and all authors worked out the main results together. $\mathrm{CH}$ started the write up with the manuscript. ISF drafted the manuscript together with $\mathrm{EE}$ and LO. All authors have critically commented on the manuscript and given final approval to the manuscript.

\section{Acknowledgements}

We would like to acknowledge the informants for sharing their stories and personnel at LHL-R for their help in recruiting participants.

\section{References}

1. Swinburn BA, Sacks G, Hall KD, McPherson K, Finegood DT, Moodie ML, Gortmaker SL. The global obesity pandemic: shaped by global drivers and local environments. Lancet 2011; 378: 804-14.

2. Wadden TA, Butryn ML, Wilson C. Lifestyle modification for the management of obesity. Gastroenterology 2007; 132(6): 2226-38.

3. Peirson L, Douketis J, Ciliska D, Fitzpatrick-Lewis D, Ali MU, Raina P. Treatment for overweight and obesity in adult populations: a systematic review and meta-analysis. CMAJ Open 2014; 2: E306-17.

4. Sharma A and lacobellis G. Treatment of obesity: a challenging task. In: Wolf G, Editor. Obesity and the Kidney. Basel: Karger, 2006, pp. 212-220.

5. Kay M, Santos J, Takane M. New horizons for health through mobile technologies. Global Observatory for eHealth series - Volume 3. World Health Organization 2011.

6. Rapp A and Cena F. Personal informatics for everyday life: how users without prior self-tracking experience engage with personal data. Int J Hum Comput Stud 2016; 94: 1-17.

7. Rich E and Miah A. Mobile, wearable and ingestible health technologies: towards a critical research agenda. Health Sociol Rev 2017; 26(1): 84-97.

8. Foster GD, Makris AP and Bailer BA. Behavioral treatment of obesity. Am J Clin Nutr 2005; 82: 230235.

9. Steinhubl SR, Muse ED and Topol EJ. Can mobile health technologies transform health care? JAMA 2013; 310(22): 2395-6.

10. Parish JM. The patient will see you now: the future of medicine is in your hands. J Clin Sleep Med 2015; 11(6): 689-690.

11. Marcengo A and Rapp A. Visualization of human behavior data: the quantified self. In: Huang ML and Huang W (eds) Innovative approaches of data visualization and visual analytics, information science reference. Hershey PA: IGI Global, 2014, pp. 236-265. 
12. de Vries HJ, Kooiman TJ, van Ittersum MW, van Brussel $M$, de Groot M. Do activity monitors increase physical activity in adults with overweight or obesity? A systematic review and meta-analysis. Obesity 2016; 24(10): 2078-91.

13. Yen HY and Chiu HL. The effectiveness of wearable technologies as physical activity interventions in weight control: a systematic review and meta-analysis of randomized controlled trials. Obes Rev 2019; 20(10): 1485-1493.

14. Pantzar M and Ruckenstein M. Social rhythms of the heart. Health Sociol Rev 2017; 26(1): 22-37.

15. Donnachie C, Wyke S, Mutrie N, Hunt K."It's like having a personal motivator that you carried around wi' you": utilising selfdetermination theory to understand men's experiences of using pedometers to increase physical activity in a weight management programme. IJBNPA 2017; 14: 61.

16. Tsigos, C, Hainer V, Basdevant A, Finer N, Fried M, Mathus-vliegen E, et al. Management of obesity in adults: European clinical practice guidelines. Obes Facts 2008; 1(2): 106-16.

17. Beck AT. Cognitive therapy: nature and relation to behavior therapy. Behav Ther 1970; 1(2): 184-200.

18. Nes BM, Gutvik C, Lavie C, Nauman J, Wisløff U. Personalized Activity Intelligence (PAI) for prevention of cardiovascular disease and promotion of physical activity. Am J Med 2017; 130(3): 328-336.

19. Braun V and Clarke V. Using thematic analysis in psychology. Qual Res Psychol 2006; 3(3): 77-101.

20. Hartmann-Boyce J, Johns DJ, Jebb SA, Ayeyard P. Behavioural Weight Management Review Group. Effect of behavioural techniques and delivery mode on effectiveness of weight management: systematic review, meta-analysis and meta-regression. Obes rev 2014; 15: 598-609.

21. Rothman AJ, Baldwin AS, Hertel AW. Self-regulation and behavior change: disentangling behavioral initiation and behavioral maintenance. In: Baumeister R and Vohs K (eds) Handbook of selfregulation: research, theory, and applications. New York: Guilford Press, 2011, pp. 106-122.

22. Prochaska JO, Redding CA and Evers KE. The transtheoretical model and stages of change. In: Glanz K, Rimer BK and Viswanath K (eds) Health behavior and health education: theory, research, and practice. San Francisco: Jossey-Bass, 2008, pp. 125-149.

23. Samdal GB, Eide GE, Barth T, Williams G, Meland E. Effective behaviour change techniques for physical activity and healthy eating in overweight and obese adults: systematic review and metaregression analyses. Int J Behav Nutr Phys Act 2017; 14(42).

24. Thomas SL, Hyde J, Karunaratne A, Kausman R, Komesaroff PA. "They all work...when you stick to them": a qualitative investigation of dieting, weight-loss, and physical exercise, in obese individuals. Nutr J 2008; 7(34).

25. Divine $\mathrm{CM}$ and Barnhill $\mathrm{A}$. The ethical and public health importance of unintended consequences: the case of behavioral weight loss interventions. Public Health Ethics 2018; 11(3): 356-361.

26. Linde JA, Rothman AJ, Baldwin AS, Jeffery RW. The impact of self-efficacy on behavior change and weight change among overweight participants in a weight loss trial. Health Psychol Rev 2006. 25: p. 282-291. 
27. Mensinger JL, Calogero RM and Tylka, TL. Internalized weight stigma moderates eating behavior outcomes in women with high BMI participating in a healthy living program. Appetite 2016; 102: 3243.

28. Venditti EM, Wylie-Rosett J, Delahanty LM, Mele L, Hoskin MA, Edelstein SL et al. Short and long-term lifestyle coaching approaches used to address diverse participant barriers to weight loss and physical activity. Int J of Behav Nutr Phys Act 2014; 11(16): 1-12.

29. Følling IS, Solbjør M and Helvik AS. Previous experiences and emotional baggage as barriers to lifestyle change - a qualitative study of Norwegian Healthy Life Centre participants. BMC Fam Pract 2015; $16: 73$.

30. Dato S, Rose G, Crocco P, Monti D, Garagnani P, Franceschi C, et al. The genetics of human longevity: an intricacy of genes, environment, culture and microbiome. Mech Ageing Dev 2017; 165: 147-155.

\section{Tables}

Table 1: Informants characteristics 


\section{Characteristics}

Sociodemographic variables

Gender

Females

Males

Age

18-29

30-39

40-49

50-59

$>60$

Civil status

Single/Separated

Partner/Married

Highest level of education

Nine years or less of school

More than nine years of school

Bachelor degree or higher

Work status

Student

Working

On disability leave

Weight-related comorbidities

$\leq 1$

2-3

$\geq 4$

Use of activity monitors at six moths

Continued with the activity monitors given to them

Changed to a preferable activity monitors of their own

Not wanting to use activity monitors
Total $(\mathrm{N}=\mathbf{2 9})$

$N(\%)$

$17(59)$

$12(41)$

$3(10)$

5 (17)

$12(42)$

$7(24)$

$2(7)$

$18(62)$

$11(38)$

$5(17)$

$13(45)$

$11(38)$

2 (7)

15 (51)

12 (42)

4 (14)

21 (72)

4 (14)

10 (34)

17 (59)

2 (7) 
Table 2: Quotes about experiences with activity monitors when changing health habits 


\section{Informants quotes}

Proof of "This watch dog [pointing at the activity monitor] reminds me to get out there and keep effort $\quad$ it up. Lately I have been walking every morning and I see the progression."

Male 50-59

years

"I use it a lot to monitor both distance and how fast I walk. Sometimes in the evenings after supper I see that I have only walked 8,000 steps, and then I have time to go out so I get the orange bar so there will be enough steps at least."

Female 40-

49 years

"It's a fabulous tool for me. But I may get too hung up on clocking these steps, mostly because I want to compete against myself, how long I spend on training and I try to get more steps and longer work-outs."

Male $40-49$ years

"I have to walk to get my job done so I use the monitor to look to see how far I have come when it is time for lunch. With more walking I become faster, and I get better time and then I will have more spare time. I'm not as tired after my work-walk anymore as I was before, but I'm 40 kilos less than I was before."

Male 50-59 years

"On the watch I can see that I've been working hard, so my mind and motivation was better in that regard. There was less focus on my pain, and more on having achieved something good for myself."

Male 20-29 years

Highlights of failure
"I have had a lot of bad conscience for neither eating proper nor being as active as I should. It is not especially motivating to see that I only move like $20 \%$ of what is recommended. The monitor keeps reminding me when I have been sitting too long, adding to my frustration, and that is just making me feel bad that I cannot do better"

29 years

Female 20-

"I was very exciting and I really wanted to try the activity monitor, but you know, when you want something and then you find that you are too big for this to, then it is a feeling that you have had many times before. After all, it was that I was too big that I could not do anything with, but I didn't need the extra reminder of that all the time."

Male 40-

49 years

"I walked much less than I thought; I'm not particularly physically active, much less than I should have done. I ended up not using it because I sat so much still; it was not exactly motivating to see that I had only moved $20 \%$."

Female 30- 
"The watch was too small, and it was hard to accept. But I changed to another one, but then I was not good enough at reaching the daily steps». In the beginning I thought that maybe it could be a motivation, but it was just the opposite, so I just had to put it away"

49 years

Female 40-

"Doing physical activity as an adult when one has been away for so many years, it became like "no, it will not work" when seldom I reached the watch' targets. I feel like, why cannot I do it anyway. I have no answer to that."

Male 50-

59 years 